\title{
Review and results of a survey about biosimilars prescription and challenges in the Middle East and North Africa region
}

Fadi Farhat ${ }^{1,2^{*}}$, Ahmad Othman ${ }^{1}$, Fadi el Karak ${ }^{2,3}$ and Joseph Kattan ${ }^{2,3}$

\begin{abstract}
Background: Only drafts of regulatory guidelines for the registration of biosimilars are available in Lebanon. We analyzed the results of a regional survey conducted in Lebanon to understand the impact of different parameters on the acceptance and future prescription of biosimilars. We also reviewed the current situation of biosimilars around the world. The study surveyed healthcare professionals from the Arab countries, Iran, Belgium and Italy. Data about the participants'specialty, country of residence, their knowledge about biosimilars, biosimilars' prescription, price influence and the manufacturer's credibility were collected.

Results: 117 questionnaires were completed and returned: 46 (39.3\%) respondents were oncologists. 72 (61.5\%) respondents were Lebanese, and the others from Egypt, Syria, Algeria, Iraq, Sudan, Jordan, Iran, Belgium and Italy. 77 (65.8\%) respondents had knowledge about biosimilars, of whom 48 (62.3\%) considered biosimilars as biologics that demonstrate bioequivalence with the original biodrug and have all preclinical and clinical trials equal to those already performed with the original biodrug. 74 (63.2\%) out of 117 respondents agreed that biosimilars in the Arab and Middle Eastern market are already marketed. Among the 48 participants who prescribe biosimilars, the main prescription driver was the drug's approval by the FDA and EMA (68.8\%). 71 (60.7\%) respondents considered that the main advantage of biosimilars is their lower price and 41 (35\%) out of the 117 respondents declared that they should know in which country the drug has been tested/created before using it in their own country. $35 \%$ of the respondents thought that the cost of a treatment should not come before its effectiveness or safety/tolerance, given that the biosimilar will be less expensive than the reference drug.

Conclusions: Biosimilars' acceptance and use is increasing worldwide. Only few physicians are aware of biosimilars presence in the market and do prescribe them in Lebanon and the Arab region. This could be mainly explained by lack of confidence in efficacy, safety, manufacturing process and price of these products, and lack of clear legislation. Thus, WHO is finalizing a new guideline for similar biotherapeutic agents. This could be a starting point for the Lebanese government to support the authorization of biosimilars.
\end{abstract}

Keywords: Biosimilars, Lebanon and Arab world markets, Prescription, Pricing

\section{Background}

Introduced into the market more than 30 years ago, biological products result from biologic material and encompass a wide range of elements such as hormones,

\footnotetext{
*Correspondence: drfadi@drfadi.org; drfadi.research@gmail.com; drfadi. clinic@gmail.com

1 Department of Hematology-Oncology, Hammoud Hospital University Medical Center, G. Hammoud Street, 652, Sidon, Lebanon

Full list of author information is available at the end of the article
}

vaccines, antibodies, proteins, polysaccharides, polynucleotides, growth factors, blood products, and live viral material; they differ greatly from chemical medicines (Liang and Mackey 2012). Biosimilars are medicinal products with a similar but not identical safety, efficacy and quality as the authorized reference (originator) biologic agents. They are composed of an analogous active substance but are large molecular-weight, complex molecules that are produced in living cells through genetic 
engineering (Sylvester et al. 2013). They are also referred to as biological and biotherapeutic agents/products.

The Biologics Price Competition and Innovation Act (BPCIA) defines biosimilar as a biological product highly similar to the reference product notwithstanding minor differences in clinically inactive components; and with no clinically meaningful differences between the biologic product and the reference product in terms of the safety, purity, and potency of the product (FDA 2009).

In this paper, we report the results of a regional survey to understand the impact of different parameters on the acceptance and future prescription of biosimilars in the Lebanese and Arab markets. We also analyze the current situation in the region and discuss the worldwide situation of biosimilars focusing mainly on the European Union (EU) and the United States (U.S.) laws, regulations and legislation pathways, pricing and challenging market access.

\section{Methods}

A regional survey was conducted from 26 to 28 March 2015 during the Pan Arab Oncology Meeting in Beirut, Lebanon. The meeting drew over 150 participants from the Arab countries, Iran, Belgium and Italy. It was attended by a wide range of healthcare professionals: oncologists, hematologists, hemato-oncologists, gynecologist, surgeons, pulmonologists, radiologists, anatomopathologists, pharmacists and others.

A two-page questionnaire of 14 questions was distributed to all the meeting participants. The survey tool collected data about the participants' specialty, country of residence, their knowledge about biosimilars, biosimilars' prescription, price influence and the manufacturer's credibility (Additional file 1). Data collected were described with frequencies and percentages using the SPSS software application (IBM Corp. Released 2014. IBM SPSS Statistics for Windows, Version 23.0. Armonk, NY: IBM Corp).

\section{Results}

In total, 117 questionnaires were completed and returned. The results of the survey showed that 46 (39.3\%) respondents were oncologists, 17 (14.5\%) were hemato-oncologists and $14(12 \%)$ were nurses while only $2(1.7 \%)$ were hematologists. The majority of the respondents were Lebanese $(61.5 \%, \mathrm{n}=72), 12 \%$ were from Egypt, 11.1\% from Syria and the others from Algeria, Iraq, Sudan, Jordan, Iran, Belgium and Italy (Table 1).

Moreover, $77(65.8 \%)$ out of the 117 respondents had knowledge about biosimilars. Among the 77 respondents who seemed to have a good understanding of scientific issues pertaining biosimilars, 48 (62.3\%) respondents considered biosimilars as biologics that
Table 1 Specialty and country of residence of the survey participants $(n=117)$

\begin{tabular}{ll}
\hline Variable & N (\%) \\
\hline Specialty & \\
Oncology & $46(39.3)$ \\
Hemato-oncology & $17(14.5)$ \\
Nurse & $14(12.0)$ \\
Surgery & $10(8.5)$ \\
Gynecology & $6(5.1)$ \\
Pharmacy & $6(5.1)$ \\
Urology & $5(4.3)$ \\
Radiology & $3(2.6)$ \\
Hematology & $2(1.7)$ \\
Anatomopathology & $1(0.9)$ \\
Other & $7(6.0)$ \\
Country of residence & \\
Lebanon & $72(61.5)$ \\
Egypt & $14(12.0)$ \\
Syria & $13(11.1)$ \\
Algeria & $8(6.8)$ \\
Iraq & $3(2.6)$ \\
Belgium & $2(1.7)$ \\
Sudan & $2(1.7)$ \\
Jordan & $1(0.9)$ \\
Iran & $1(0.9)$ \\
Italy & $1(0.9)$ \\
\hline
\end{tabular}

demonstrate bioequivalence with the original biodrug and have all preclinical and clinical trials equal to those already performed with the original biodrug. Besides, when approved, they already have a well-defined immunogenicity.

As for biosimilars' prescription, 74 (63.2\%) out of 117 respondents agreed that biosimilars in the Arab and Middle Eastern market are already marketed. In parallel, 53 (45.3\%) respondents agreed that biosimilars are being manufactured in the same region. In addition, 48 (41\%) respondents confirmed that they prescribe biosimilars versus 38 (32.5\%) who do not prescribe them. Among the 48 participants who prescribe biosimilars, the main driver for prescribing them was the drug's approval by the Food and Drug Administration (FDA) and the European Medicines Agency (EMA) (68.8\%), followed by a lower price of the bioequivalence in comparison with the innovator (64.6\%), then bioefficacy (47.9\%), safety (41.7\%), good manufacturing practices and high reputation of the manufacturer (31.3\%).

As for the price influence, $35 \%$ of the respondents thought that the cost of a treatment should not come before its effectiveness or safety/tolerance, given that the biosimilar will be less expensive than the reference 
drug. In contrast, $25.6 \%$ thought that the lower prices of the biosimilar are a good news because patients will be treated with biologics, and would help cost savings (26.5\%).

The results also showed that physicians would mainly trust a company highly experienced in manufacturing small-molecule generic drugs as a producer of biosimilars (48.7\%), knowing that they have the expertise to deal with regulatory authorities and have the knowledge of approval's guidelines. Interestingly, physicians will trust more a company with prior experience in manufacturing biologics as a manufacturer of biosimilars (54.7\%) (Table 2).

\section{Discussion}

Our survey marks the acceptance of physicians to a biosimilar submitted and responding to EMA and FDA regulations. Our finding complies with international results where PubMed-indexed manuscripts and grey literature reported the acceptance of prescribing FDA-approved biosimilars by almost all physicians surveyed. These physicians also believe that the FDA-approved biosimilars have the same efficacy (effectiveness) and safety profile as the originator biological (Felix et al. 2014).

Pricing is still a key factor and cost saving also seemed to be an important driver for prescribing biosimilars (26.5\%). We note that some biosimilars are marketed at a reduced price, compared to the innovator. Such low price can only be explained by a trivial investigational cost, thus the absence of adequate comparative studies. Consequently, efficacy and safety of such drugs are questionable. EMA and FDA commonly reject these drugs for lack of scientific criteria of safety. Recognition and authorization from legal entities is crucial for physicians, to encourage them to prescribe biosimilars, but what will influence the prescriber? Is it patients, fellows or the health system? In fact, the major factor influencing the prescriber is the payer. This is the case in organizations where the health authorities can force the prescriber, and where the substitution of the innovator is applied. Thus, this proves the doubt in biosimilars efficacy and safety by physicians in addition to the unwillingness to prescribe biosimilars unless mandatory. Ultimately, the credibility of the biosimilar is the main driver for the launch of any biosimilar in the Arab world. While literature reports that the manufacturers may use higher rebates on originator biologicals as a barrier to adopting biosimilars (Felix et al. 2014), we aim to investigate in future surveys what prescribing behavior would have changed had the price levels been specifically examined. Also, our next survey will focus on understanding how Lebanese and Arab health care professionals perceive an adequate level of "trust" in the medication, namely how much a discount makes this affordable and testing whether prescribers are aware of the pricing/payor factors in their own regions as regards to biosimilars.

In the following sections, we summarize the main points about the biosimilars' regulations and challenging market access in USA and the European countries as well as Lebanon.

\section{Biosimilars worldwide \\ Regulations and laws}

The U.S., EU, Japan, Canada and the pharmerging markets (China, India, Brazil and Mexico) form geographically the market for biologics and biosimilars. Each of these markets has its own regulations and laws concerning biosimilars. EU has led the way in developing a legal framework for the approval of biosimilar products via EMA.

As for the U.S., several conditions make the US as the biggest opportunity for biosimilars to extremely progress by 2020 such as the presence of competing and leading manufacturers (Pfizer and Merck), patients and health insurers needing the access to low-cost, high-value drugs. Thus, this opportunity will be the cut-off point for the success or failure of biosimilars in the next decade (Kresse 2009; IMS Health 2011).

EU guidelines EMA is held accountable for the scientific assessment of medicines for use in EU countries, and for the approval of all medicines for human and animal use derived from biotechnology and other high-tech processes including biosimilars. Those guidelines concerning biosimilars' requirements for the market approval have been dictated by the EMA in accordance with the funds of the Community Code. They enclose the following: (1) the original product must be authorized within the EU, (2) the 8 years data exclusivity of the reference must be expired, (3) the similarity between the safety, efficacy and quality of the biosimilar and the original biologic product must have been demonstrated, (4) the primary amino acid arrangement of the biosimilar protein has to be matching to the reference product amino acid sequence, (5) the biosimilar manufacturer needs to validate each step of development, comparative but possibly abbreviated non-clinical pharmacology and toxicology studies, human Pharmacokinetics (PK) and Pharmacodynamics (PD) studies and human efficacy and safety studies including immunogenicity, and (6) the Risk Management Plan must include pharmacovigilance (IMS Health 2011; Church et al. 2009; Choy and Jacobs 2014).

Since October 2006 till present, EMA has approved 21 biosimilars corresponding to 8 active molecules, in six categories of biologics (epoetins, filgrastims, follitropins, growth hormones, insulins, and monoclonal antibodies) (European Medicines Agency 2016) (Table 3). 
Table 2 Knowledge about biosimilars and their prescription $(n=117)$

\begin{tabular}{|c|c|c|}
\hline Questionnaire item & $\mathrm{N}(\%)$ & N (\%) \\
\hline \multicolumn{3}{|l|}{ Knowledge about biosimilars } \\
\hline \multicolumn{3}{|l|}{ Do you know what biosimilars are? } \\
\hline Yes & $77(65.8)$ & \\
\hline No & $14(12.0)$ & \\
\hline No answer & $26(22.2)$ & \\
\hline \multicolumn{3}{|l|}{ Choose one item that adjusts to your concept of biosmilars $^{\text {a }}$} \\
\hline $\begin{array}{l}\text { A biologic that demonstrates bioequivalence with the original biodrug and has all preclinical and clinical trials equal } \\
\text { to those already performed with the original biodrug. Besides, when approved, it already has a well-defined immu- } \\
\text { nogenicity }\end{array}$ & $48 / 77(62.3)$ & \\
\hline $\begin{array}{l}\text { A biologic that demonstrates bioequivalence with an original biodrug and does not need clinical trials to be com- } \\
\text { mercialized }\end{array}$ & $12 / 77(15.6)$ & \\
\hline A molecule equal to that of the original biologic but of lower production cost & $17 / 77(22.1)$ & \\
\hline An attempt to copy an innovative biodrug and will never be equal to it & $1 / 77(1.3)$ & \\
\hline A generic biologic of an already commercialized biodrug & $4 / 77(5.2)$ & \\
\hline \multicolumn{3}{|l|}{ Biosimilars' prescription } \\
\hline \multicolumn{3}{|l|}{ Do you agree with the information that there are already marketed biosimilars in the Arab and Middle Eastern Market? } \\
\hline Yes & $74(63.2)$ & \\
\hline No & $22(18.8)$ & \\
\hline No answer & $21(17.9)$ & \\
\hline \multicolumn{3}{|l|}{ Do you agree with the information that biosimilars are being manufactured in the Arab and Middle Eastern Market? } \\
\hline Yes & $53(45.3)$ & \\
\hline No & $38(32.5)$ & \\
\hline No answer & $26(22.2)$ & \\
\hline \multicolumn{3}{|l|}{ Do you prescribe biosimilars? } \\
\hline Yes & $48(41.0)$ & \\
\hline No & $38(32.5)$ & \\
\hline No answer & $31(26.5)$ & \\
\hline \multicolumn{3}{|l|}{ What are the major drivers that encourage you to prescribe biosimilars? } \\
\hline Safety & $20 / 48(41.7)^{\mathrm{b}}$ & $40 / 117(34.2)^{c}$ \\
\hline Bioefficacy & $23 / 48(47.9)^{b}$ & $45 / 117(38.5)^{c}$ \\
\hline FDA and EMA approval for biosimilar & $33 / 48(68.8)^{\mathrm{b}}$ & $61 / 117(52.1)^{c}$ \\
\hline Good manufacturing practices and high reputation of the manufacturer & $15 / 48(31.3)^{b}$ & $31 / 117(26.5)^{c}$ \\
\hline Country of origin of the biosimilars' manufacturer & $14 / 48(29.2)^{\mathrm{b}}$ & $25 / 117(21.4)^{c}$ \\
\hline Lower price of the bioequivalence in comparison with the innovator & $31 / 48(64.6)^{\mathrm{b}}$ & $58 / 117(49.6)^{c}$ \\
\hline Nothing encourages you & $2 / 48(4.2)^{b}$ & $6 / 117(5.1)^{c}$ \\
\hline \multicolumn{3}{|l|}{ What are the major local drivers that encourage you to prescribe biosimilars? } \\
\hline Assurance that phase III clinical trials will be performed in a sample of the local population & $14 / 48(29.2)^{b}$ & $33 / 117(28.2)^{c}$ \\
\hline Maintenance of an adequate national system of pharmacovigilance specific to biosimilars & $23 / 48(47.9)^{\mathrm{b}}$ & $36 / 117(30.8)^{c}$ \\
\hline Transparency of the local health regulatory authority(ies) & $16 / 48(33.3)^{\mathrm{b}}$ & $34 / 117(29.1)^{c}$ \\
\hline Nothing encourages you & $7 / 48(14.6)^{b}$ & $14 / 117(12.0)^{c}$ \\
\hline \multicolumn{3}{|l|}{ In your opinion, what are the advantages of a biosimilar? } \\
\hline Lower price & $71 / 117(60.7)$ & \\
\hline $\begin{array}{l}\text { Commercialization approved with initial indication including all diseases previously approved for the innovative } \\
\text { biodrug }\end{array}$ & $32 / 117(27.4)$ & \\
\hline Administration route different from that of the original biodrug & 10/117 (8.5) & \\
\hline Lower therapeutic dose & $8 / 117(6.8)$ & \\
\hline There are no advantages & $6 / 117(5.1)$ & \\
\hline \multicolumn{3}{|l|}{ Now that biosimilars are coming to the market, you think that ${ }^{d}$} \\
\hline Patient associations should be informed and should be able to give their opinion & 28/117 (23.9) & \\
\hline Patients should systematically be given information & 28/117 (23.9) & \\
\hline
\end{tabular}


Table 2 continued

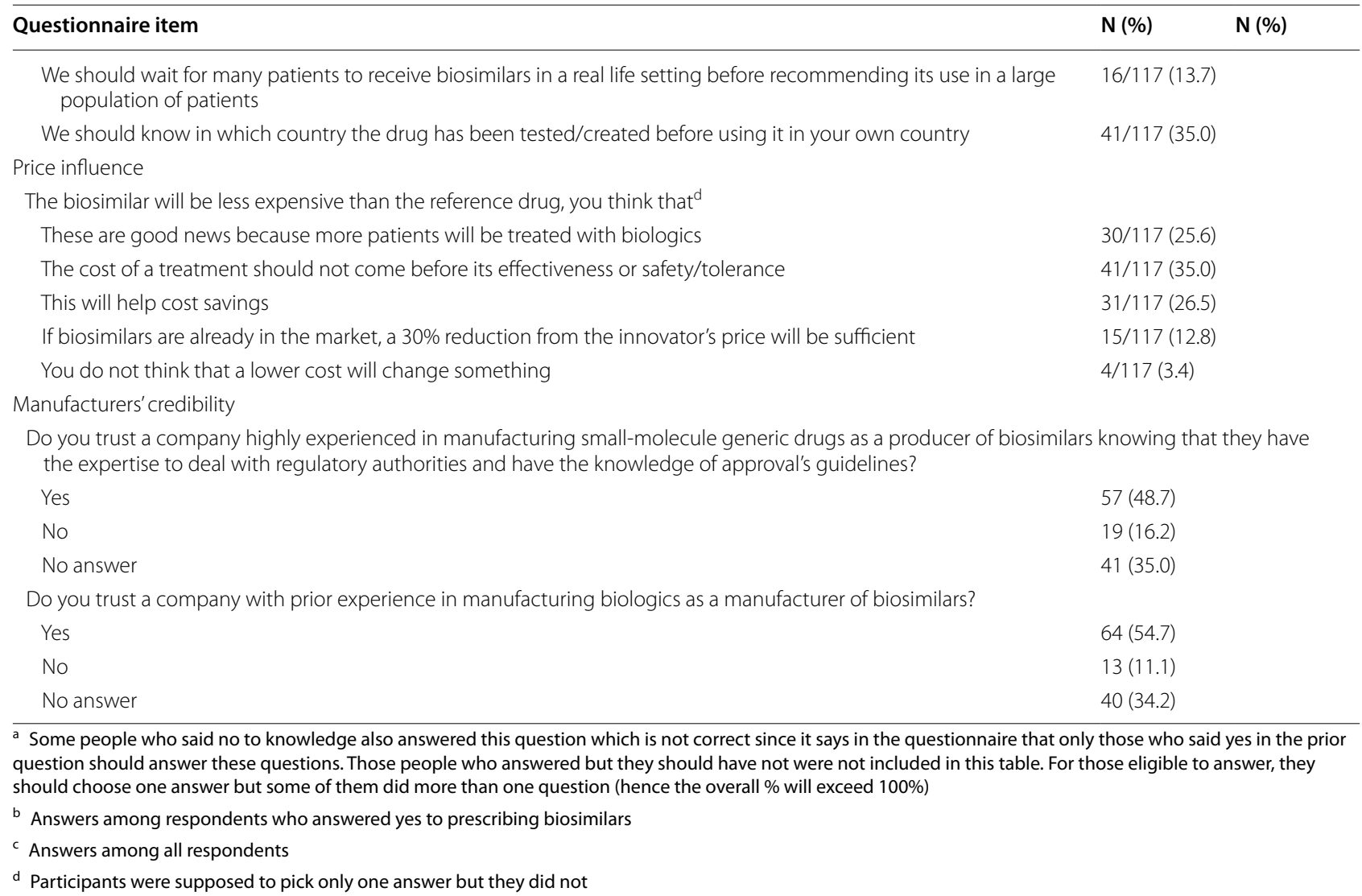

Moreover, substitutability and interchangeability differ from a country to another in the EU, each having implemented its own legislation. For instance, France and Italy exclude substitution of innovative biologics by biosimilars, United Kingdom (UK) restricts these substitutions. Hence, the European biopharmaceutical industries are asking for demonstration and a clear differentiation of the concepts of similarity and interchangeability (IMS Health 2011).

U.S. guidelines Since 2006, the FDA has approved biological products based on comparability such as Omnitrope, Enoxatrapine and Genotropin. It is only in 2010, after obtaining the Patient Protection and Affordable Care (PPAC) Act signed by President Obama, that the US had the authority to approve biosimilars (FDA 2010). The 2009 BPCIA formally passed under the PPAC Act, an amendment of the Public Health Service Act (PHS Act) reduced approval pathway for biological agents that showed to be greatly similar (biosimilar) to a FDA approved biological product. The BPCIA is theoretically comparable to the Drug Price Competition and Patent Term Restoration Act of 1984 that created biological drug approval through the Federal Food, Drug, and Cosmetic Act (FFD\&C Act). The
BPCIA supports the FDA's long-lasting policy that allows adequate trust on the known information about a drug, thus saving time, resources and avoiding the repetition of already available human or animal tests (Nick 2012).

Another important part of the amendment in the PPAC Act for biosimilars is the exclusivity of the data. Data exclusivity is the time frame between biosimilar filling on the innovator data. It is designed to protect the innovation taking into consideration the time-consuming, expensive and uncertain process involved during the waiting period of the innovator to gain the FDA approval. The data exclusivity time ranges between 12 and 14 years (US Code 2012).

In April 2015, the FDA released 2 highly-anticipated guidances on biosimilars. The first guidance "Scientific Considerations in Demonstrating Biosimilarity to a Reference Product" assists companies in demonstrating that a proposed therapeutic protein product is biosimilar to a reference product for the purpose of submitting an application, called a "351(k)" application, to the FDA. It also describes a risk-based "totality-of-the-evidence" approach that the FDA intends to use to evaluate the data and information submitted in support of a determination of biosimilarity of the proposed product 
Table 3 EMA approved biosimilars (European Medicines Agency 2016)

\begin{tabular}{|c|c|c|c|}
\hline Date of biosimilar EMA approval & Biosimilar product & Original product & Active substance \\
\hline 12 April 2006 & Omnitrope & Genotropin & Somatropin \\
\hline 28 August 2007 & Abseamed & Epogen/Eprex & Epoetin alfa \\
\hline 28 August 2007 & Binocrit & Epogen/Eprex & Epoetin alfa \\
\hline 28 August 2007 & Epoetin Alfa Hexal & Epogen/Eprex & Epoetin alfa \\
\hline 18 December 2007 & Silapo & Epogen/Eprex & Epoetin zeta \\
\hline 18 December 2007 & Retacrit & Epogen/Eprex & Epoetin zeta \\
\hline 15 September 2008 & Biograstim & Neupogen & Filgrastim \\
\hline 15 September 2008 & Ratiograstim & Neupogen & Filgrastim \\
\hline 15 September 2008 & Tevagrastim & Neupogen & Filgrastim \\
\hline 06 February 2009 & Filgrastim Hexal & Neupogen & Filgrastim \\
\hline 06 February 2009 & Zarzio & Neupogen & Filgrastim \\
\hline 08 June 2010 & Nivestim & Neupogen & Filgrastim \\
\hline 10 September 2013 & Inflectra & Remicade & Infliximab \\
\hline 27 September 2013 & Ovaleap & Gonal-f & Follitropin alfa \\
\hline 10 October 2013 & Remsima & Remicade & Infliximab \\
\hline 18 October 2013 & Grastofil & Neupogen & Filgrastim \\
\hline 27 March 2014 & Bemfola & Gonal-f & Follitropin alfa \\
\hline 09 September 2014 & Abasaglar (previously Abasria) & Lantus & Insulin glargine \\
\hline 18 September 2014 & Accofil & Neupogen & Filgrastim \\
\hline 14 January 2016 & Benepali & Enbrel & Etanercept \\
\hline 26 May 2016 & Flixabi & Remicade & Infliximab \\
\hline
\end{tabular}

to the reference product (U.S. Department of Health and Human Services et al. 2015a). The second guidance entitled "Quality Considerations in Demonstrating Biosimilarity to a Reference Protein Product" provides an overview of analytical factors to consider when assessing biosimilarity between a proposed therapeutic protein product and a reference product for the purpose of submitting a 351(k) application. This includes the importance of extensive analytical, physico-chemical and biological characterization in demonstrating that the proposed biosimilar product is highly similar to the reference product notwithstanding minor differences in clinically inactive components (U.S. Department of Health and Human Services et al. 2015b). Also in May 2015, the FDA released a draft guidance on "Biosimilars: Questions and Answers Regarding Implementation of the Biologics Price Competition and Innovation Act of 2009". This guidance document is being distributed for comment purposes only and provides answers to common questions from people interested in developing biosimilar products. The question and answer format addresses questions that may arise in the early stages of product development, such as how to request meetings with the FDA, addressing differences in formulation from the reference product, how to request exclusivity, and other topics (U.S. Department of Health and Human Services et al. 2016).
As of 05 October 2016, the FDA authorized 4 biosimilars (Table 4).

\section{Pricing and challenging market access}

Biosimilars' sales are projected to reach around \$25-\$35 billion by 2020 . Since the first biosimilar approval in EU in 2006, 21 biosimilars are now authorized by the EMA (European Medicines Agency 2016) (Table 3), 4 biosimilars by the FDA (Table 4), and 250 biosimilars are in the pipeline globally (Deloitte 2015). This market is growing tremendously in spite of the effort to reduce the global healthcare costs, which is making it the fastest rising market of all biologics sector in the next 5 years (IMS Health 2011).

This increase in spending was estimated to $700 \%$ between 2010 and 2015, summing up to approximately $\$ 80$ billion in global sales to replace branded biologic agents losing their patent by 2015 (Liang and Mackey 2012). Consequently, switching to biosimilars would help in saving billions of dollars annually. This is expected to reach $\$ 40-\$ 250$ billion in the coming 10 years in the U.S. alone (Deloitte 2015). However, the expected success and progress of biosimilars in Europe is higher than the US markets due to the presence of general and specific guidelines. Other factors such as comparability studies (quality, efficacy and safety), substitution, pricing and reimbursement may affect biosimilars market 
Table 4 FDA approved biosimilars

\begin{tabular}{|c|c|c|c|}
\hline Date of biosimilar FDA approval & Biosimilar product & Original product & Active substance \\
\hline $\begin{array}{l}06 \text { March } 2015 \text { (U.S. Department of Health and Human Services and Food and Drug } \\
\text { Administration 2016a) }\end{array}$ & Zarxio & Neupogen & Filgrastim \\
\hline $\begin{array}{l}05 \text { April } 2016 \text { (U.S. Department of Health and Human Services and Food and Drug } \\
\text { Administration 2016b) }\end{array}$ & Inflectra & Remicade & Infliximab \\
\hline $\begin{array}{l}30 \text { August } 2016 \text { (U.S. Department of Health and Human Services and Food and Drug } \\
\text { Administration 2016c) }\end{array}$ & Erelzi & Enbrel & Etanercept \\
\hline $\begin{array}{l}23 \text { September } 2016 \text { (U.S. Department of Health and Human Services and Food and Drug } \\
\text { Administration 2016d) }\end{array}$ & Amjevita & Humira & Adalimumab \\
\hline
\end{tabular}

accessibility (Simoens et al. 2011). Thus, we assume that switching to biosimilars does not consider "biobetter" prescribing, where a better biologic will still be priced higher, and prescribers will likely lean toward the more effective biologic.

Moreover, due to the high research and developmental cost of biosimilars, the difference of prices between them and the reference biological agent is supposed to be less compared to the reference and generics. In fact biosimilars are priced $30 \%$ less than the originator compared to a reduction of $80 \%$ for the generics after the first 6 months to years after its entry to the market. Although this reduction may not be significant but seems to be sufficient to generate high profitable rates (Lockwood et al. 2013).

However, the biosimilar market is not easy to access given the challenges in terms of regulatory uncertainty production complexity, interchangeability and competition. In particular, the lack of clear guidelines on interchangeability and substitutability with reference biologics will probably cause physicians to be more cautious in prescribing biosimilars until they gain comfort with the efficacy and quality of biosimilars (Deloitte 2015). These entry barriers for manufacturers should be crossed to penetrate a highly competitive platform, yet cost-effective. Thus, for a positive entry to the biosimilar market, few major abilities should be accomplished such as adequate research and development capabilities, specific biomanufacturing platforms, legal expertise and international distribution channels, global network of marketing sales and a robust lobbying with regulatory organizations, opinion leaders, governments and key people to facilitate the approval of laws and regulations (Calo-Fernandez and Martinez-Hurtado 2012).

\section{Biosimilars in Lebanon}

\section{Indications and consumption}

Lebanon's healthcare sector is considered as one of the best in the Middle East and North Africa (MENA) region. Many biosimilars are being used, as in the global market, such as granulocyte colony stimulating factor (G-CSF) frequently prescribed in the hemato-oncology field. The list also includes erythropoietin given to patients with chronic renal failure or oncological ailments, Humira ${ }^{\circledR}$, Remicade $^{\circledR}$ and Enbrel ${ }^{\circledR}$ in rheumatoid arthritis, psoriasis, and other immunological diseases.

A 2006 report by the World Health Organization (WHO) about the Health System Profile in Lebanon showed that the total health expenditure of Gross Domestic Products is about 12\% (World Health Organization 2006). However, being expensive therapeutic drugs, biosimilars are not accessible for all Lebanese population. Hence, major imported oncological drugs to the Lebanese market were studied in terms of cost and consumption to show their impact on total budget.

\section{Guidelines: laws and regulations}

To assure the biosafety and efficacy of biosimilars, the Lebanese Ministry of Public Health (MOPH) decided to develop requirements and guidance for registration of biosimilar drugs. Those were drafted in 2013 and follow the EMA guidelines, WHO and International Conference for Harmonization (ICH) Guidance on Similar Biological Products in collaboration with the French National Agency for Medicines and Health Products safety (Agence Nationale de Securité des Médicaments, ANSM) (CTD format) (Republic of Lebanon 2013). Consequently, a special committee to propose amendments to the decree $571 / 2008$ concerning the regulatory guidelines for biosimilar medicinal products in Lebanon was formed. While waiting for the committee approval and an update of legal texts, the approval of biosimilars follows same rules as generics. Neither the "Requirements for Drug Substance and Finished Product Checklist" nor the "Requirements for Bioequivalence Study Checklist" requested analysis specific to the biosimilars are present. Biosimilars, as separate category is not even mentioned for the time being.

The "General Regulatory and Manufacturing Rules" state in the decree 571 that "the international authorities 
that should be followed for approval of registration are the FDA, the American Medical Association (AMA) and WHO. The drug that will be approved should also be registered in at least 2 countries". Based on the following decision of the MOPH, prices are established based on the price in the country of origin with comparison to the established median price in many European countries such as France, UK, Belgium, Switzerland, Italy, Spain and Portugal. But nothing is mentioned concerning the pricing of biosimilars per se.

\section{Challenges}

Every country in the Arab world has a different health system and has its own laws concerning registration of new drugs. Drug patent, protecting brands and innovators differ as well. For instance in Jordan, any generic can be introduced in the Jordanian market after 3 years of launching in the country where it was first approved (Jordan Food and Drug Administration 2016), while in Lebanon the drug's patent follows the international guidelines. This difference can be explained by the fact that not all countries are member of the World Trade Organization (WTO).

With the approaching patent expiration of major biopharmaceutical products and the emerging growth of biosimilars in global markets, issues will arise due to the fact that biological products or biosimilars are different from the small generic drugs. Safety concerns will surface again unless biosimilars prove to have a comparable safety profile. Alike other countries, prescriptions of biosimilars in Lebanon and the Arab world will face many challenges, especially the patient and physician's trust in the medication per se, the affordability, accessibility and availability issues.

\section{Conclusions}

Biosimilars' acceptance and use is growing worldwide. Despite this accomplishment, only the EU via EMA and US FDA have dictated specific regulations and guidelines related to biosimilars. Only few physicians are aware of biosimilars presence in the market and do prescribe them. Further investigations must be carried out to find out whether this is ascribed to lack of confidence in efficacy, safety, manufacturing process and price of these products. Lack of clear legislation is likely to be responsible for the low rate of awareness about biosimilars; thus, WHO is finalizing a new group of guidelines for similar biotherapeutic agents. This is intended to help national regulatory agencies, manufacturers, and other interested parties and could be a starting point for the Lebanese government to support the authorization of biosimilars.

\section{Additional file}

Additional file 1. Survey questionnaire.

\begin{abstract}
Abbreviations
AMA: American Medical Association; ANSM: Agence Nationale de Securité des Médicaments (French National Agency for Medicines and Health Products safety); EMA: European Medicines Agency; EU: European Union; FDA: Food and Drug Application; FFD\&C: Federal Food, Drug, and Cosmetic; G-CSF: granulocyte colony stimulating factor; ICH: International Conference for Harmonization; MENA: Middle East and North Africa; MOPH: Ministry of Public Health; PD: pharmacodynamics; PHS: Public Health Service; PK: pharmacokinetics; PPAC: Patient Protection and Affordable Care; UK: United Kingdom; U.S.: United States; WHO: World Health Organization; WTO: World Trade Organization.
\end{abstract}

\section{Authors' contributions}

FF wrote the article, the survey questionnaire and analyzed the data. AO and FeK reviewed and revised substantively and critically the second version of the paper. JJ reviewed the article. All authors read and approved the final manuscript.

\section{Author details}

${ }^{1}$ Department of Hematology-Oncology, Hammoud Hospital University Medical Center, G. Hammoud Street, 652, Sidon, Lebanon. ${ }^{2}$ Faculty of Medicine, Saint Joseph University, Beirut, Lebanon. ${ }^{3}$ Department of Medical Oncology, Hôtel-Dieu de France University Hospital, Beirut, Lebanon.

\section{Acknowledgements}

We thank all healthcare professionals who participated in the survey. We are also thankful for Ms. Racha Aaraj from Phoenix Clinical Research for her assistance in medical writing.

\section{Competing interests}

The authors declare that they have no competing interests.

\section{Availability of data and materials}

Database and questionnaires completed by the survey participants are available upon request from the corresponding author.

Received: 3 June 2016 Accepted: 1 December 2016

Published online: 30 December 2016

\section{References}

Calo-Fernandez B, Martinez-Hurtado JL (2012) Biosimilars: company strategies to capture value from the biologics market. Pharmaceuticals 5:1393-1408

Choy E, Jacobs IA (2014) Biosimilar safety considerations in clinical practice. Semin Oncol 41:S3-S14

Church RF, Druckman MN, Wright E (2009) Biosimilars: What differences between the EU and the US? Scrip World Pharmaceuticals News Supplement

Deloitte (2015) Winning with biosimilars Opportunities in global markets. http://www2.deloitte.com/content/dam/Deloitte/us/Documents/lifesciences-health-care/us-Ishc-biosimilars-whitepaper-final.pdf. Accessed 17 May 2016

European Medicines Agency (2016) European public assessment reports. http://www.ema.europa.eu/ema/index.jsp?curl=pages\%2Fmedicines\%2 Flanding\%2Fepar_search.sp\&mid=WC0b01ac058001d124\&searchTab=s earchByAuthType\&alreadyLoaded=true\&isNewQuery=true\&status=Aut horised\&keyword=Enter+keywords\&searchType=name\&taxonomyPath $=\&$ treeNumber $=\&$ searchGenericType=biosimilars\&genericsKeywordSea rch $=$ Submit. Accessed 05 Oct 2016 
FDA (2009) Biologics price competition and innovation act of 2009. Technica report, Food and Drug Administration, Silver Spring, MD, USA

FDA (2010) Approval pathway for biosimilar and interchangeable biological products public meeting. http://www.fda.gov/Drugs/NewsEvents/ ucm221688.htm. Accessed 17 May 2016

Felix AE, Gupta A, Cohen JP, Riggs K (2014) Barriers to market uptake of biosimilars in the US. GaBI J 3(3):108-115

IMS Health (2011) Shaping the biosimilars opportunity: a global perspective on the evolving biosimilars landscape. http://www.imshealth.com/ims/ Global/Content/Home\%20Page\%20Content/IMS\%20News/Biosimilars_ Whitepaper.pdf. Accessed 17 May 2016

Jordan Food and Drug Administration (2016) laws and regulations. http:// www.jfda.jo/. Accessed 17 May 2016

Kresse GB (2009) Biosimilars-Science, status and strategic perspective. Eur J Pharm Biopharm 72:479-486

Liang B, Mackey T (2012) Tipping point: Biosimilars, emerging markets, and public-private engagement to promote global health. J Commer Biotechnol 18:65-74

Lockwood C, Reinaud F, Marinoni G, Ando G (2013) Biosimilar and originator biologic pricing, dynamics in emerging markets. HIS Healthcare and Pharma. http://www.ihs.com/pdfs/Biologics-Emerging-Markets-oct-2013. pdf. Accessed 17 May 2016

Nick C (2012) The US biosimilars act: challenges facing regulatory approval. Pharm Med 26(3):145-152

Republic of Lebanon (2013) Ministry of Public Health. Quality Assurance of Pharmaceutical Products Program Implementation. Dr. Rita Karam ESA 2013. http://www.moph.gov.lb/Media/Documents/QAPP.pdf. Accessed 17 May 2016

Simoens S, Verbeken G, Huys I (2011) Market access of biosimilars: not only a cost issue. Oncologie 13(5):218-221

Sylvester K, Rocchio M, Beik N, Fanikos J (2013) Biosimilars: an emerging category of biologic drugs for emergency medicine practitioners. Curr Emerg Hosp Med Rep 1:226-235

US Code (2012) Legal Information Institute, 42 U.S. Code § 262-Regulation of biological products. http://www.law.cornell.edu/uscode/text/42/262. Accessed 17 May 2016

U.S. Department of Health and Human Services, Food and Drug Administration (2016a) News \% Events. FDA approves first biosimilar product Zarxio. http://www.fda.gov/newsevents/newsroom/pressannouncements/ ucm436648.htm. Accessed 05 Oct 2016
U.S. Department of Health and Human Services, Food and Drug Administration (2016b) News \% Events. FDA approves Inflectra, a biosimilar to Remicade. http://www.fda.gov/newsevents/newsroom/pressannouncements/ucm494227.htm. Accessed 05 Oct 2016

U.S. Department of Health and Human Services, Food and Drug Administration (2016c) News \% Events. FDA approves Erelzi, a biosimilar to Enbrel. http://www.fda.gov/newsevents/newsroom/pressannouncements/ ucm518639.htm. Accessed 05 Oct 2016

U.S. Department of Health and Human Services, Food and Drug Administration (2016d) News \% Events. FDA approves Amjevita, a biosimilar to Humira. http://www.fda.gov/NewsEvents/Newsroom/PressAnnouncements/ucm522243.htm. Accessed 05 Oct 2016

U.S. Department of Health and Human Services, Food and Drug Administration, Center for Drug Evaluation and Research (CDER), Center for Biologics Evaluation and Research (CBER) (2015a) Scientific Considerations in Demonstrating Biosimilarity to a Reference Product Guidance for Industry April 2015. Biosimilarity. http://www.fda.gov/downloads/Drugs/GuidanceComplianceRegulatoryInformation/Guidances/UCM291128.pdf. Accessed 17 May 2016

U.S. Department of Health and Human Services, Food and Drug Administration, Center for Drug Evaluation and Research (CDER), Center for Biologics Evaluation and Research (CBER) (2015b) Quality Considerations in Demonstrating Biosimilarity of a Therapeutic Protein Product to a Reference Product Guidance for Industry. Biosimilarity. http://www.fda.gov/downloads/Drugs/GuidanceComplianceRegulatorylnformation/Guidances/ UCM291134.pdf. Accessed 17 May 2016

U.S. Department of Health and Human Services, Food and Drug Administration, Center for Drug Evaluation and Research (CDER), Center for Biologics Evaluation and Research (CBER) (2016) Biosimilars: Additional Questions and Answers Regarding Implementation of the Biologics Price Competition and Innovation Act of 2009 Guidance for Industry Draft Guidance. http://www.fda.gov/downloads/Drugs/GuidanceComplianceRegulatoryInformation/Guidances/UCM273001.pdf. Accessed 17 May 2016

World Health Organization (2006) Regional health systems observatory-EMRO. Health system profile: Lebanon. http://hinfo.humaninfo.ro/gsdl/healthtechdocs/documents/s17301e/s17301e.pdf. Accessed 17 May 2016

\section{Submit your manuscript to a SpringerOpen ${ }^{\odot}$ journal and benefit from:}

- Convenient online submission

- Rigorous peer review

- Immediate publication on acceptance

- Open access: articles freely available online

- High visibility within the field

- Retaining the copyright to your article

Submit your next manuscript at springeropen.com 